\title{
Oxidative Stress and Increased Type-IV Collagenase Levels in Bronchoalveolar Lavage Fluid from Newborn Babies
}

\author{
BETTINA C. SCHOCK, DAVID G. SWEET, MADELEINE ENNIS, JANE A. WARNER,
} IAN S. YOUNG, AND HENRY L. HALLIDAY

\begin{abstract}
Departments of Clinical Biochemistry [B.C.S., M.E., I.S.Y.] and Child Health [D.G.S., H.L.H.], Institute of Clinical Science, The Queen's University of Belfast, Belfast BT12 6BJ, Northern Ireland, U.K., and School of Biological Sciences, University of Southampton, Biomedical Sciences Building, Southampton SO16 7PX,
\end{abstract} U.K. [J.A.W.]

\begin{abstract}
Oxidative stress may increase lung permeability by upregulation of matrix-metalloproteinase-9 (MMP-9), a type-IV collagenase that can disrupt alveolar basement membranes. We have compared a marker of oxidative stress (protein carbonyl residues) with levels of MMP-9 and its inhibitor, tissue inhibitor of metalloproteinase-1 (TIMP-1), in bronchoalveolar lavage samples from newborn babies. Bronchoalveolar lavage samples ( $n=87$, two from each time point) were taken in the first 6 postnatal days from 41 ventilated babies: 18 of $<29$ wk gestation, 10 of 29-36 wk, 9 term with persistent fetal circulation, and 4 term without lung disease. Respiratory disease severity at the time of bronchoalveolar lavage was assessed using the arterialalveolar oxygen tension ratio. One sample from each time point was used for the measurement of MMP-9 by zymography and TIMP-1 by ELISA. The second sample was used to measure carbonyl group concentrations, also using an ELISA. Correlations were calculated between protein carbonyls, arterialalveolar oxygen tension ratio, and MMP-9 and TIMP-1 concentrations. Significant correlations were found between carbonyl
\end{abstract}

\section{ABSTRACT}

concentrations and arterial-alveolar oxygen tension ratio $(r=$ $-0.325, p=0.0031, n=81)$, MMP-9 $(r=0.331, p<0.0029$, $n=79)$, and TIMP-1 $(r=0.436, p<0.0001, n=87)$. Worsening respiratory disease in newborn babies is associated with increased carbonyl concentrations in neonatal bronchoalveolar lavage fluid, and these correlated with MMP-9 and TIMP-1 levels. Increased oxidative stress may damage the lung by increasing type-IV collagenase activity, causing disruption of the extracellular matrix. (Pediatr Res 50: 29-33, 2001)

$\quad$ Abbreviations
a/A ratio, arterial-alveolar oxygen tension ratio
BAL, bronchoalveolar lavage
CLD, chronic lung disease
IQR, interquartile range
MDA, malondialdehyde
MMP-9, matrix metalloproteinase-9
TIMP-1, tissue inhibitor of metalloproteinase-1

Newborn babies with lung disease are often exposed to high inspired oxygen concentrations to maintain sufficient arterial oxygen saturation. In preterm babies this is most often owing to surfactant deficiency, but severe respiratory problems also occur in term babies, particularly those with persistent fetal circulation (1). High oxygen concentrations increase the rate of oxygen free radical formation (reactive oxygen species), and these highly reactive molecules can cause oxidative damage to proteins, DNA, lipids, cells, and tissues (2). Antioxidant defense mechanisms are poorly developed in the preterm baby and in term babies may be

Received June 13, 2000; accepted November 7, 2000.

Correspondence and reprint requests: H.L. Halliday, M.D., Perinatal Room, Royal Maternity Hospital, Grosvenor Road, Belfast BT12 6BB, Northern Ireland; e-mail: h.halliday@qub.ac.uk

Supported by a grant from the Northern Ireland Mother \& Baby Action. overcome by the generation of excessive reactive oxygen species (3). Oxidative stress is a major contributing factor to the development of CLD (3).

The link between oxidative stress and lung inflammation has been extensively studied in animal models. Exposure of rats to $100 \%$ oxygen produces a lethal injury within $72 \mathrm{~h}$ characterized by increased permeability of the alveolarcapillary barrier and interstitial and pulmonary edema. MMP-9 has been implicated in this hyperoxic lung damage $(4,5)$. TIMP-1 is the major inhibitor of MMP-9, and its expression is also increased by hyperoxia (6). Conversely, TIMP-1 can also be oxidized, thereby rendering it ineffective (7).

In this observational study, we have assessed whether oxidative stress in the newborn baby is associated with increased BAL fluid concentrations of MMP-9 and TIMP-1. 


\section{METHODS}

Subjects. This was a prospective study of babies born in the Royal Maternity Hospital in Belfast between March 1998 and April 1999. The study was approved by the Research Ethics Committee of The Queen's University of Belfast, and parental consent was obtained before babies were enrolled. Babies were eligible for study if they required intubation and mechanical ventilation within the first $6 \mathrm{~d}$ of life. Gestation was estimated by duration of amenorrhea combined with early prenatal ultrasound measurement. Forty-one babies were studied, and 18 of them were born before 29 wk gestation, 10 were 29-36 wk, 9 were term babies with persistent fetal circulation, and 4 were term babies without significant lung disease, ventilated for hypoxic ischemic encephalopathy, oversedation, congenital myopathy, or gastroschisis. The severity of the respiratory disease at the time of BAL sampling was quantified using the a/A ratio. This was calculated from arterial blood gases using the formula a/A ratio $=\mathrm{Po}_{2} /\left(94 \times \mathrm{Fio}_{2}\right)-\mathrm{PCO}_{2}$, where $\mathrm{Po}_{2}$ and $\mathrm{PCO}_{2}$ are expressed in $\mathrm{kPa}$ and $\mathrm{Fio}_{2}$ (fraction of inspired oxygen) as a fraction of 1 . The median a/A ratio using all arterial blood gases in the first $24 \mathrm{~h}$ of life was used to estimate initial respiratory disease severity. In the 18 very preterm babies, CLD was defined as a requirement for supplemental oxygen to maintain oxygen saturation measured by pulse oximetry $>92 \%$ when at rest after the 36th week after conception.

$\boldsymbol{B} \boldsymbol{A} \boldsymbol{L}$. BAL was performed in a standardized way using a well-established technique (8). In summary, $1 \mathrm{~mL} / \mathrm{kg}$ of sterile $0.9 \%$ saline was instilled using a syringe via a $5 \mathrm{~F}$ feeding catheter, which had been placed through the endotracheal tube into the distal right main bronchus. The saline was instilled and immediately aspirated back into the syringe. The sample was clarified by centrifugation at $1500 \times \mathrm{g}$ for $5 \mathrm{~min}$ at room temperature, and the supernatant was immediately frozen at $-70^{\circ} \mathrm{C}$ for subsequent analysis. On each occasion this was repeated twice, with the first sample used for measurement of MMP-9 and TIMP-1, and the second sample for measurement of carbonyl group concentrations. Serial BAL was performed daily whenever possible from the time of intubation until extubation or the sixth day of life, whichever was soonest. Babies were not studied during the $12 \mathrm{~h}$ after a dose of surfactant.

MMP-9. MMP-9 concentrations were measured by zymography (9). SDS (7.5\% SDS-PAGE) gels were copolymerized with $0.1 \%$ gelatin, and the proteins in $8 \mu \mathrm{L}$ of BAL (diluted $1: 5$ in PBS) were separated electrophoretically. The gels were then rinsed in Tris-Triton buffers to remove the SDS, incubated overnight in Tris- $\mathrm{HCl}, \mathrm{pH} 7.6$, containing $10 \mathrm{mM} \mathrm{CaCl}_{2}$ and $1 \%$ Triton, and then stained with Coomassie blue. After destaining with a solution of $7.5 \%$ acetic acid and $5 \%$ methanol, the MMP activity was visualized as clear bands on a blue background. The intensity of the bands was estimated using computerized image analysis and densitometry. If MMP-9 was undetectable, then the gels were rerun using undiluted BAL samples. The limit of detection was $0.5 \mathrm{ng} / \mathrm{mL}$. Coefficients of variation were $4.5 \%$ (intragel) and $9.6 \%$ (intergel). When the measured MMP-9 concentration was below the detection limit of the assay, it was substituted with a value equal to the detection limit for statistical analysis.

TIMP-1. TIMP-1 (Amersham Pharmacia, Amersham, U.K.) was measured using a commercially available ELISA. The limit of detection was $1.56 \mathrm{ng} / \mathrm{mL}$. Coefficients of variation were $4.8 \%$ (intraplate) and $7.9 \%$ (interplate).

Protein carbonyls. Carbonyl concentrations were determined using an in-house ELISA as described by Buss et al. (10). Briefly, after derivatization of carbonyl groups with dinitrophenylhydrazine, proteins were adsorbed to 96-well ELISA plates, captured with a commercially available antidinitrophenylhydrazine antibody, and detected with a horseradish peroxidase/hydrogen peroxide, phenylenediamine system (10). The limit of detection was $0.28 \mathrm{nmol} / \mathrm{mg}$ protein. Coefficients of variation were $8.6 \%$ (intraplate) and $9.3 \%$ (interplate).

Protein assay. Total protein concentrations in BAL fluid were quantified using the commercially available BioRad kit (BioRad Laboratories LTD., U.K.). The detection limit was 2 $\mu \mathrm{g} / \mathrm{mL}$.

MDA assay. MDAs were determined by HPLC with fluorimetric detection after reaction with thiobarbituric acid (11). The limit of detection was $0.03 \mu \mathrm{mol} \mathrm{MDA} / \mathrm{L}$. Coefficients of variation were $9.5 \%$ (intraassay) and $9.4 \%$ (interassay).

Data analysis. The distribution of the concentrations of MMP-9, TIMP-1, and protein carbonyls were all highly negatively skewed but normally distributed when plotted logarithmically. Nonparametric tests were used throughout. Results were considered statistically significant if $p<0.05$. To compute all statistics, StatView for Windows (v. 4.57, 1996, Abacus Concepts Inc., Berkeley, CA, U.S.A.) was used. For graphs, GraphPad Prism (v.2.01, GraphPad Software Inc., San Diego, CA, U.S.A.) was used.

\section{RESULTS}

A total of 87 BAL samples from 41 babies were analyzed. The clinical characteristics of the babies and the number of BAL samples from each of the groups are shown in Table 1. The median volume recovered after lavage was 0.7 (IQR, $0.5-1.2) \mathrm{mL}$. The term babies with persistent fetal circulation had the highest requirements for supplemental oxygen and the lowest median a/A ratio on $\mathrm{d} 1(p<0.0001)$. There was no statistically significant difference in the median day of sampling among the groups (median, $3 \mathrm{~d}$ for both preterm groups, $4 \mathrm{~d}$ for term persistent fetal circulation, and $3.5 \mathrm{~d}$ for term normal; $p=0.37$ ).

Protein carbonyl groups, MDAs, and TIMP-1 were detected in all 87 BAL samples. In eight cases there was insufficient volume of BAL fluid for both TIMP-1 and MMP-9 assays, thus MMP-9 was measured in only 79 samples. In 18 samples MMP-9 was undetectable even when using undiluted BAL fluid. Simultaneous a/A ratios were available for 81 samples as six babies did not have blood gas analysis at the time of BAL.

The results for protein carbonyls, MDAs, MMP-9, TIMP-1, and TIMP-1/MMP-9 ratio for all subgroups are given in Tables 2 and 3. The results are shown as median and IQR. Protein carbonyl concentrations were significantly different among the 
Table 1. Clinical characteristics and initial respiratory disease severity of babies

\begin{tabular}{|c|c|c|c|c|c|c|}
\hline Group & $\begin{array}{l}\text { Babies } \\
\qquad(n)\end{array}$ & $\begin{array}{l}\text { Gestation (wk) } \\
\text { mean (SD) }\end{array}$ & $\begin{array}{l}\text { Weight }(\mathrm{g}) \\
\text { mean }(\mathrm{SD})\end{array}$ & $\begin{array}{l}\text { Median a/A ratio d } 1 \\
\text { mean }(\mathrm{SD})\end{array}$ & $\begin{array}{c}\text { Maximum } \mathrm{FIO}_{2} \text { d } 1 \\
\text { median }(\mathrm{IQR})\end{array}$ & $\begin{array}{c}\text { BAL samples } \\
(n)\end{array}$ \\
\hline \multicolumn{7}{|l|}{ Preterm } \\
\hline 24-28 wk & 18 & $26.0(1.2)$ & $895(251)$ & $0.43(0.18)$ & $0.60(0.37-0.83)$ & 44 \\
\hline \multicolumn{7}{|l|}{ Term } \\
\hline PFC & 9 & $39.0(1.6)$ & 3261 (427) & $0.20(0.11)^{*}$ & $1.00(0.78-1.00)$ & 16 \\
\hline Normal lung & 4 & $37.5(1.0)$ & 3067 (513) & $0.71(0.09)$ & $0.21(0.21-0.21)$ & 10 \\
\hline
\end{tabular}

Results shown as mean (SD) and median (IQR) for $\mathrm{FIO}_{2}$.

PFC, persistent fetal circulation.

$* p<0.05$ [term PFC vs term normal, preterm (29-36 wk), and very preterm (24-28wk].

Table 2. Concentrations of markers of oxidative stress in BAL fluid of all babies studied*

\begin{tabular}{ccccc}
\hline Group & $\begin{array}{c}\text { Total } \\
\text { protein } \\
(\mu \mathrm{g} / \mathrm{mL})\end{array}$ & $\begin{array}{c}\text { Carbonyl } \\
\text { groups } \\
(\mathrm{nmol} / \mathrm{mg})\end{array}$ & $\begin{array}{c}\text { Carbonyl } \\
\text { groups } \\
(\mathrm{nmol} / \mathrm{mL})\end{array}$ & $\begin{array}{c}\text { MDAs } \\
(\mu \mathrm{mol} / \mathrm{L})\end{array}$ \\
\hline Preterm & & & & \\
$24-28 \mathrm{wk}$ & 0.28 & 2.93 & 0.56 & 0.16 \\
& $(0.12-0.44)$ & $(2.26-3.76)$ & $(0.38-1.03)$ & $(0.05-0.49)$ \\
$29-36 \mathrm{wk}$ & 0.32 & 2.94 & 0.93 & 0.10 \\
& $(0.27-0.46)$ & $(1.60-3.82)$ & $(0.67-1.20)$ & $(0.03-3.11)$ \\
Term & & & & \\
PFC & 0.50 & 2.07 & 1.10 & 0.41 \\
& $(0.23-1.15)$ & $(1.11-3.10)$ & $(0.38-2.29)$ & $(0.14-2.11)$ \\
Normal lung & 0.25 & 1.17 & 0.31 & 0.31 \\
& $(0.14-0.40)$ & $(0.89-1.52)$ & $(0.15-0.77)$ & $(0.18-0.53)$ \\
\hline
\end{tabular}

Results are given as median (IQR).

PFC, persistent fetal circulation.

* Statistical analyses were performed using Kruskal-Wallis one-way ANOVA and showed significant differences among the groups for protein carbonyls (nmol/mg, $p<0.001$ and $\mathrm{nmol} / \mathrm{mL}, p<0.05$ ).

Table 3. Concentrations of MMP-9, TIMP-1, and TIMP-1/MMP-9 ratio in BAL fluid of all babies studied

\begin{tabular}{cccc}
\hline Group & $\begin{array}{c}\text { MMP-9 } \\
(\mathrm{ng} / \mathrm{mL})\end{array}$ & $\begin{array}{c}\text { TIMP-1 } \\
(\mathrm{ng} / \mathrm{mL})\end{array}$ & $\begin{array}{c}\text { TIMP-1/ } \\
\text { MMP-9 ratio }\end{array}$ \\
\hline Preterm & & & \\
$24-28 \mathrm{wk}$ & 45.21 & 136.10 & 2.89 \\
& $(6.10-130.1)$ & $(59.56-248.90)$ & $(0.69-31.93)$ \\
29-36 wk & 38.90 & 233.90 & 8.16 \\
& $(8.40-83.30)$ & $(116.2-325.10)$ & $(1.68-19.96)$ \\
Term & & & \\
PFC & 25.45 & 233.10 & 5.63 \\
Normal lung & $(0.49-301.60)$ & $(59.35-595.20)$ & $(1.29-121.10)$ \\
& $(5.88-70.62)$ & $(47.35-208.10)$ & $(1.08-12.74)$ \\
\hline
\end{tabular}

Results are given as median (IQR).

PFC, persistent fetal circulation.

* Statistical analyses were performed using Kruskal-Wallis one-way ANOVA and showed no significant differences among the groups.

groups (Kruskal-Wallis one-way ANOVA, nanomoles per milligram; $p<0.001$ and nanomoles per milliliter; $p<0.05$ ).

Worsening respiratory disease, demonstrated by a lower a/A ratio, was associated with increased BAL fluid concentrations of protein carbonyls $(r=-0.325, p=0.0031, n=81$; Fig. 1$)$. There was a significant correlation between protein carbonyl concentrations and MMP-9 $(r=0.331, p=0.0031, n=79$; Fig. 2$)$ and TIMP-1 ( $r=0.436, p<0.0001, n=87$; Fig. 3$)$ concentrations in BAL fluid. These correlations did not remain significant when protein carbonyl data were expressed as nano-

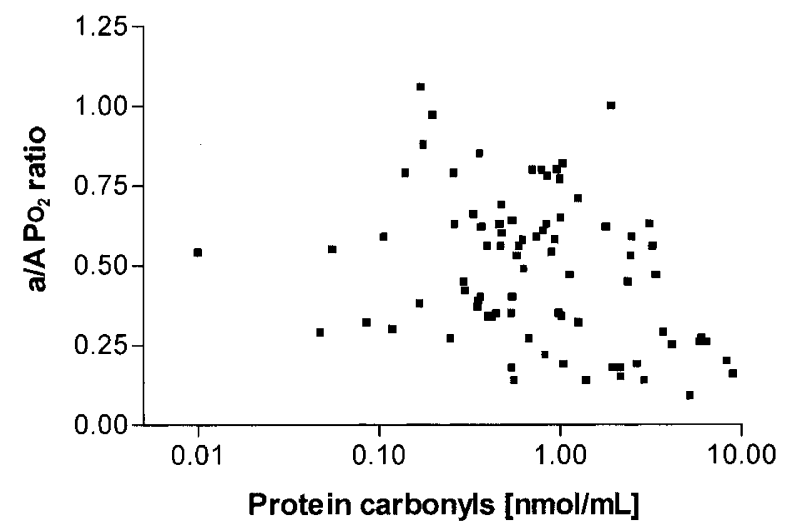

Figure 1. Association between concentration of protein carbonyl groups (nanomoles per milliliter) and disease severity $\left(\mathrm{a} / \mathrm{A} \mathrm{Po}_{2}\right.$ ratio) in BAL fluid of all babies studied: $r=-0.325, p=0.0031, n=81$. Statistical analyses were performed using Spearman's correlation coefficient. Note the logarithmic scale for protein carbonyls.

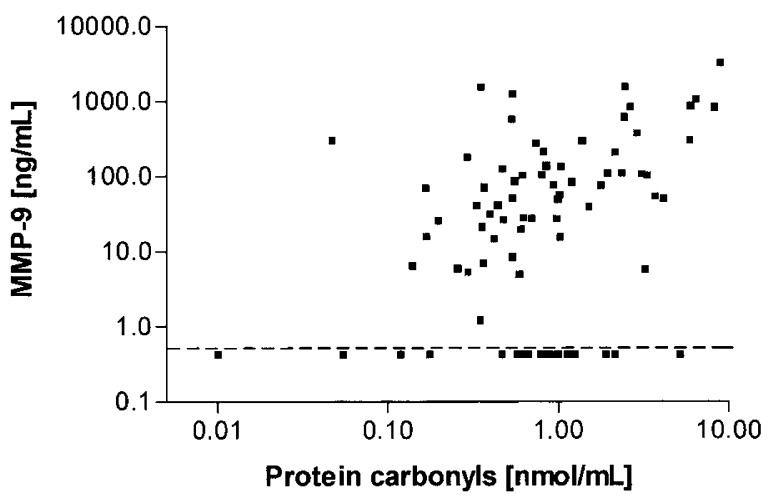

Figure 2. Association between concentrations of protein carbonyl groups (nanomoles per milliliter) and MMP-9 (nanograms per milliliter) in BAL fluid of all babies studied: $r=0.331, p=0.0029, n=79$. Statistical analyses were performed using Spearman's correlation coefficient. The dashed line marks the detection limit of the assay, $0.5 \mathrm{ng} / \mathrm{mL}$. Note the logarithmic scale for both axes.

moles per milligram of protein $(r=-0.109,-0.136$, and -0.127 respectively; all $p>0.05$ ). Protein carbonyl concentrations did not correlate with changes in the ratio of MMP-9 to TIMP-1 concentrations in neonatal BAL fluid ( $r=0.144, p$ $=0.206, n=79)$. MMP-9 and TIMP- 1 concentrations were weakly, but significantly, correlated $(r=0.318, p=0.005, n$ $=79)$.

In contrast to protein carbonyl concentrations, MDAs did not correlate significantly with concentrations of MMP-9 ( $r=$ 


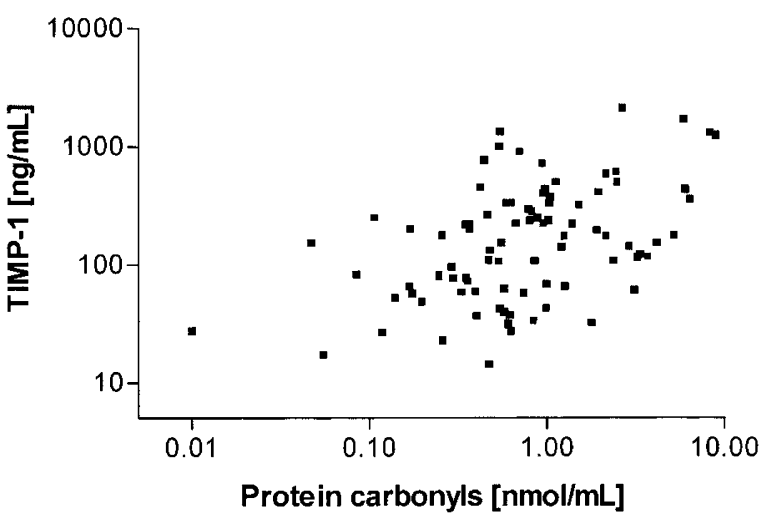

Figure 3. Association between concentrations of protein carbonyl groups (nanomoles per milliliter) and TIMP-1 (nanograms per milliliter) in BAL fluid of all babies studied: $r=0.436, p<0.0001, n=87$. Statistical analyses were performed using Spearman's correlation coefficient. Note the logarithmic scale for both axes.

$0.077, p=0.516, n=74)$ or TIMP-1 $(r=0.048, p=0.671$, $n=81)$. MDAs also did not correlate with concentrations of protein carbonyls $(r=0.122, p=0.278, n=81)$.

When analyzing the 44 BAL samples from the 18 very preterm babies in isolation, there was no significant correlation between carbonyl groups and a/A ratio $(r=-0.132, p=$ $0.394, n=44)$ or MMP-9 $(r=0.300, p=0.067, n=38)$. There was, however, a significant correlation between carbonyl groups and TIMP-1 $(r=0.407, p=0.0061, n=44)$. Eight babies in this group had CLD (24 BAL samples) and 10 did not (20 BAL samples). There was no significant difference in concentrations of protein carbonyls, MDAs, MMP-9, and TIMP-1 in BAL fluid from this small group of babies with and without CLD, although the median MDA concentration was more than $3 \times$ higher in babies who had CLD compared with those who did not $[0.38(0.05-0.57)$ versus $0.10(0.03-0.38)$ $\mu \mathrm{mol} / \mathrm{L}]$. Additionally, a trend was apparent for increased concentrations of protein carbonyls $[0.78(0.45-1.14)$ versus $0.47(0.35-0.59) \mathrm{nmol} / \mathrm{mL}, p=0.079]$.

\section{DISCUSSION}

There is a clear link between oxidative stress and the lung inflammation that occurs during the development of CLD in the preterm baby (3). The exact mechanisms of oxidative lung injury are not fully elucidated, and most studies of reactive oxygen species-mediated lung damage have used in vitro systems or animal models. Reactive oxygen species inhibit DNA synthesis, leading to diminished lung growth $(12,13)$. They oxidize both lipids (14) and proteins (15) in surfactant, rendering it less effective. Surfactant synthesis can also be inhibited by oxidative stress (16). Oxidation of $\alpha-1$ proteinase inhibitor leads to its inactivation, which can predispose to excessive elastase activity (17). Indeed, Speer et al. (18) detected considerable free elastase activity in tracheal aspirate fluid in 42 of 140 ventilated neonates, with a pronounced increase in risk of pulmonary interstitial emphysema for those with free elastase activity. There may also be other damaging effects on the proteins within the epithelial lining structures of the lung predisposing to inflammation.
Recently it has become clear that matrix metalloproteinases play a key role in lung inflammation and airways remodelling (19). Alveolar basement membranes are composed of type-IV collagen, the major substrate of MMP-9. Preterm babies who subsequently exhibit CLD have higher MMP-9 levels in BAL fluid within the first 6 postnatal days compared with those who do not have CLD (20). Disruption of the alveolar basement membrane results in the increased lung permeability observed in adults exposed to high oxygen concentrations (21) and in babies who exhibit CLD (22). In animal studies, oxygen toxicity has been shown to increase both MMP-9 mRNA transcription (23) and lung MMP-9 levels (4, 5).

Oxidative stress is difficult to quantify directly as the very short half-lives of reactive oxygen species mean that they cannot easily be measured. However, using an artificial system, Gerber et al. (24) found that there was an enhanced generation of hydroxyl radicals in bronchoalveolar secretions from preterm infants compared with buffer, demonstrating the lack of a hydroxyl radical scavenger system in these infants. In free radical modification of proteins, carbonyl groups are introduced to some amino acid residues, and the concentration of these has been used as a measure of protein oxidative damage (25). Polyunsaturated fatty acids are modified by oxidation to peroxides, which can be quantified as MDAs (11). Measuring oxidation products in BAL fluid is ideal as it allows for the balance between the amount of reactive oxygen species exposure and the antioxidant defenses. Measuring inspired oxygen exposure in isolation would not take into account the antioxidant defenses that are probably more developed in the term babies. The amount of protein carbonylation on d 2-4 of life has previously been shown to be inversely proportional to gestational age and is significantly increased in babies who have CLD, even when controlled for gestational age (26). The finding in this study that carbonyl group concentrations in neonatal BAL fluid are correlated with the degree of respiratory disease severity is in keeping with these previous studies. The loss of significance when the protein carbonyl data are given as nanomoles per milligram of protein can be explained on the basis of increasing microvascular permeability and protein leakage into the airways during the first few days of life in preterm infants with severe respiratory distress syndrome (22). Recently, higher protein carbonyl concentrations in tracheal aspirates from preterm babies with a birthweight of $<1500$ g compared with those $>1500$ g have been shown (27). Carbonyl concentrations in our study are overall higher than those of Buss et al. (27). In our group of very preterm babies, carbonyl concentrations during d 1-3 of life were significantly elevated compared with those found at d 4-6 of life.

A relation between increased lipid peroxidation and the development of CLD is supported by the finding of increased concentrations of pentane and ethane (products of lipid peroxidation) in exhaled air (28-30) and increased concentrations of lipid peroxidation products (MDAs) in tracheal aspirates of babies who subsequently exhibited CLD (31). In this study no significant differences in MDA concentrations were found. However, the median MDA concentration in BAL fluid of babies who subsequently exhibit CLD is almost $3 \times$ higher than that in babies who do not have CLD. The difference was 
not statistically significant, but this relationship should be explored in a larger study. Intriguingly, protein carbonyl concentrations did not correlate with concentrations of lipid peroxidation. Buss et al. (27) reported a weak correlation between both markers of oxidative stress in their group of preterm babies. In preterm babies surfactant lipids are a major source of lipids in the lungs. The immature lungs are just beginning to synthesize surfactant (protein and lipid) within type II cells (32). Surfactant therapy in preterm babies may lead to similar lipid and MDA concentrations to those in term babies.

We did not correct our results for the dilution during the lavage procedure and have expressed our data per milliliter of lavage fluid as recommended by the European Respiratory Society Task Force on BAL in children (33). Our procedure for collection of BAL fluid is more likely to sample the lower airways whereas most other studies have been performed on tracheal aspirates $(22,27,31)$, which sample the upper airways.

In this study the total levels of MMP-9 and TIMP-1 have been measured. However, this does not necessarily reflect enzyme activity. MMP-9 is released as a proenzyme, which is activated in the tissues by proteolytic cleavage (34). In the assay used in this study, total MMP-9 activity is measured, including the proenzyme and any MMP-9 that is bound to TIMP-1. Similarly, the TIMP-1 ELISA measures all TIMP-1 present, including any that may be inactivated or bound to MMP-9. Our study suggests that oxidative stress to proteins increases the expression of both MMP-9 and its main inhibitor, TIMP-1. This is in keeping with previously published animal studies $(4,5,6)$. It does not, however, address the question of whether oxidative stress modifies proteinase/antiproteinase balance. Oxygen toxicity also activates pro-MMP-3, a proteinase that activates the latent form of MMP-9 (35). Similarly, oxidative stress can inactivate TIMP-1 (6). Although the ratio of MMP-9 to TIMP-1 levels did not alter with increasing oxygen toxicity, the methods used do not enable determination of changes in net enzyme activity.

In conclusion, we have shown a correlation between clinical respiratory disease severity and carbonyl concentrations in BAL fluid from newborn babies, both term and preterm, taken within the first $6 \mathrm{~d}$ of life. This suggests that carbonyl concentrations can be used as a measure of oxidative stress in this population. We have also shown a significant correlation between carbonyl concentrations and MMP-9 and TIMP-1 concentrations. This suggests that MMP-9 and TIMP-1 are upregulated by oxidative stress in newborn babies, as they are in animal models. Increased expression of type-IV collagenase during oxidative stress may result in disruption of the alveolar basement membrane, which leads to the increased capillary leakage and airways remodelling observed in the early stages of CLD.

\section{REFERENCES}

1. Greenough A, Roberton NRC 1999 Acute respiratory disease in the newborn. In: Rennie JM, Roberton NRC (eds) Textbook of neonatology, 3rd Ed. Churchill Livingstone, Edinburgh, pp 481-537

2. Freeman BA, Crapo JD 1982 Free radicals and tissue injury. Lab Invest 47:412-426

3. Saugstad OD 1997 Bronchopulmonary dysplasia and oxidative stress: are we closer to an understanding of the pathogenesis of BPD? Acta Paediatr 86:1277-1282
4. Pardo A, Selman M, Ridge K, Barrios R, Sznajder JI 1996 Increased expression of gelatinases and collagenase in rat lungs exposed to $100 \%$ oxygen. Am J Respir Crit Care Med 154:1067-1075

5. Pardo A, Barrios R, Maldonado V, Melendez J, Perez J, Ruiz V, Segura-Valdez L, Sznajder JL, Selman M 1998 Gelatinases A and B are upregulated in rat lungs by subacute hyperoxia: pathogenetic implications. Am J Pathol 153:833-844

6. Horowitz S, Dafni N, Shapiro DL, Holm BA, Notter RH, Quible DJ 1989 Hyperoxic exposure alters gene expression in the lung. Induction of the tissue inhibitor of metalloproteinases mRNA and other mRNAs. J Biol Chem 264:7092-7095

7. Frears ER, Zhang Z, Blake DR, OConnell JP, Winyard PG 1996 Inactivation of tissue inhibitor of metalloproteinase-1 by peroxynitrite. FEBS Letts 381:21-24

8. Kotecha S, Chan B, Azam N, Silverman M, Shaw RJ 1995 Increase in interleukin-8 and soluble intercellular adhesion molecule-1 in broncho-alveolar lavage fluid from premature infants who develop chronic lung disease. Arch Dis Child 72:F90-F96

9. Kleiner DE, Stetler-Stevenson WG 1994 Quantitative zymography: detection of picogram quantities of gelatinases. Anal Biochem 218:325-329

10. Buss H, Chan TP, Sluis KB, Domigan NM, Winterbourn CC 1997 Protein carbonyl measurement by a sensitive ELISA method. Free Radic Biol Med 23:361-366

11. Young IS, Trimble ER 1991 Measurement of malondialdehyde in plasma by high performance liquid chromatography with fluorimetric detection. Ann Clin Biochem 28:504-508

12. Han RNN, Buch S, Tseu I, Young J, Christie NA, Frndova H, Lye SJ, Post M, Tanswell AK 1996 Changes in structure, mechanics, and insulin-like growth factor gene expression in the lungs of newborn rats exposed to air or $60 \%$ oxygen. Pediatr Res 39:921-929

13. Wilborn A, Evers LB, Canada AT 1996 Oxygen toxicity to the developing lung of the mouse: role of reactive oxygen species. Pediatr Res 40:225-232

14. Bracci R 1997 Free oxygen radicals and surfactant. Biol Neonate 71(suppl 1):23-27

15. Haddad IY, Ischiropoulos H, Holm BA, Beckman JS, Baker JR, Matalon S 1993 Mechanisms of peroxynitrite-induced injury to lung surfactants. Am J Physiol 265:L555-L564

16. Holm BA, Matalon S, Finkelstein JN, Notter RH 1988 Type II pneumocyte changes during hyperoxic lung injury and recovery. J Appl Physiol 65:2672-2678

17. Ossanna PJ, Test ST, Matheson NR, Regiani S, Weiss SJ 1986 Oxidative regulation of neutrophil elastase-alpha-1-proteinase inhibitor interactions. J Clin Invest $77: 1939-1951$

18. Speer CP, Ruess D, Harms K, Herting E, Gefeller O 1993 Neutrophil elastase and acute pulmonary damage in neonates with severe respiratory distress syndrome. Pediatrics 91:794-799

19. O'Connor CM, FitzGerald MX 1994 Matrix metalloproteases and lung disease. Thorax 49:602-609

20. Sweet DG, Pizzoti J, Wilbourn M, Halliday HL, Warner JA 1999 Matrix metalloproteinase-9 (MMP-9) in the airways of infants at risk of developing chronic lung disease (CLD). Eur Respir J 14(suppl 30):248s

21. Griffith DE, Holden WE, Morris JF, Min LK, Krishnamurthy GT 1986 Effects of common therapeutic concentrations of oxygen on lung clearance of ${ }^{99 \mathrm{~m}} \mathrm{Tc}$ DTPA and bronchoalveolar lavage albumin concentration. Am Rev Respir Dis 134:233-237

22. Groneck P, Götze-Speer B, Oppermann M, Eiffert H, Speer CP 1994 Association of pulmonary inflammation and increased microvascular permeability during the development of bronchopulmonary dysplasia: a sequential analysis of inflammatory mediators in respiratory fluids of high risk preterm neonates. Pediatrics 93:712-718

23. Devaskar UP, Taylor W, Govindrajan R, Malicdem M, Heyman S, deMello DE 1994 Hyperoxia induces interstitial (type I) and increases type IV collagenase mRNA expression and increases type I and IV collagenolytic activity in newborn rat lung. Biol Neonate 66:76-85

24. Gerber CE, Bruchelt G, Stegmann H, Schwiensberg F, Speer CP 1999 Presence of bleomycin-detectable free iron in the alveolar system of preterm infants. Biochem Biophys Res Commun 257:218-222

25. Gladstone I, Levine R 1994 Oxidation of protein in neonatal lungs. Pediatrics 93:764-768

26. Varsila E, Pesonen E, Andersson S 1995 Early protein oxidation in the neonatal lung is related to development of chronic lung disease. Acta Paediatr 84:1296-1299

27. Buss IH, Darlow BA, Winterbourn CC 2000 Elevated protein carbonyls and lipid peroxidation products correlating with myeloperoxidase in tracheal aspirates from premature infants. Pediatr Res 47:640-645

28. Varsila E, Hallman M, Andersson S 1994 Free-radical-induced lipid peroxidation during the early neonatal period. Acta Paediatr 83:692-695

29. Nycyk JA, Drury JA, Cooke RWL 1998 Breath pentane as a marker for lipid peroxidation and adverse outcome in preterm infants. Arch Dis Child 79:F67-F69

30. Pitkänen OM, Hallman M, Andersson SM 1990 Correlation of free oxygen radicalinduced lipid peroxidation with outcome in very low birth weight infants. J Pediatr 116:760-764

31. Schrod L, Neuhaus T, Speer CP, Girschick H 1997 Possible role of uric acid as an antioxidant in premature infants. Biol Neonate 72:102-111

32. Hislop A 1996 Foetal and postnatal anatomical development. In: Greenough A, Roberton NRC, Milner AD (eds) Neonatal respiratory disorders. Arnold, Hodder Headline Group, London, pp 3-12

33. ERS Task Force on Bronchoalveolar Lavage in Children 2000 Bronchoalveolar lavage in children. Eur Respir J 15:217-231

34. Davidson JM 1990 Biochemistry and turnover of lung interstitium. Eur Respir J 3:1048-1068

35. Nagase H 1997 Activation mechanisms of matrix metalloproteinases. Biol Chem $378: 151-160$ 